\title{
DOUTRINA
}

\section{ALGUMAS NOTAS SOBRE ÓRGÃOS CONSTITUCIONALMENTE AUTÔNOMOS \\ (UM ESTUDO DE CASO SOBRE OS TRIBUNAIS DE CONTAS NO BRASIL)}

\author{
Diogo de FigueIREdo Moreira NeTO ${ }^{1}$
}

1. Introdução e método. 2. Condição plural do poder na sociedade e no estado democrático contemporâneos. 3. O poder estatal e sua distribuição orgânico-funcional na teoria constitucional. 4. O caso da natureza e taxinomia juspolítica dos tribunais de contas. 5. Exposição da natureza e taxinomia juspolíticas dos tribunais de contas. 6. Conclusões.

\section{Introdução e método}

Há uma diferença entre compreender a Ciência como uma representação objetiva do real e compreendê-la como uma maneira subjetiva de ver a realidade.

Essa afirmação se põe como uma distinção abissal a separar-nos do positivismo empírico, que foi hegemônico por quase um século, a nos fazer crer, com sua visão mecanicista, muito ao gosto do racionalismo novecentista, que a Ciência era um espelho do real, e que, em conseqüência, o Direito, tampouco, passaria de um conhecimento empírico, processualizado, depurado de desejos, de aspirações e de valores, pois de outro modo não seria "científico".

Em consequiência, o positivismo jurídico se jactava de prescindir das expressões dos desejos, das aspirações e dos valores que impulsionam o agir e que enriquecem as Ciências do Homem. ${ }^{2}$

O equívoco do racionalismo positivista residia em não reconhecer algo muito simples e apotegmático: que a própria realidade também é constituída por esses

1 Exposição apresentada no Encontro de Tribunais de Contas, realizado no Rio de Janeiro, em 30 de março de 2001.

2 Cf. MICHEL TROPER, Pour une théorie juridique de l'État, Paris, PUF, Collection Léviathan, 1994, pp.34 e 35.

R. Dir. Adm.,

Rio de Janeiro, 223: 1-24, jan./mar. 2001 
desejos, aspirações e por valores, que os sublimam e que são captados nos princípios jurídicos.

Esta é a razão pela qual, de modo similar ao que se está passando nos demais ramos do Conhecimento, começa a predominar uma visão epistemológica mais modesta, considerando que a validade das proposições científicas é sempre provisória, flexibilizando-se, modificando-se e atualizando-se constantemente em função do tempo e de suas circunstâncias aplicativas.

Explica-se assim porque a teoria positivista do Direito perdeu vigência, em um mundo em que os novos fenômenos eclodem incessantemente e passam por aceleradas mutações, que nela já não encontram lugar e explicação.

E já se contam em grande número e são cada vez mais fascinantes esses novíssimos fenômenos juspolíticos, entre os quais pode-se destacar o pluralismo das fontes normativas, a regulação autônoma, o direito supranacional, o público não estatal, a importância jurídica da efetividade das normas, o repensamento da natureza do poder reformador constitucional ${ }^{3}$ e, sobretudo, entre tantos outros, o alçamento universal dos principios à categoria de normas jurídicas, para conformar um supersistema axiologicamente orientado.

Esse supersistema, na medida em que se vem desenvolvendo, se mostra tão pujante a ponto de, hoje, orientar e justificar o amplo espectro de controle que exercem os juizes constitucionais, mesmo em sistemas tão diversos como o continental europeu o anglo-saxônico, até quando está em questão o próprio pressuposto kelseniano da racionalidade do legislador. ${ }^{4}$

É, também, esse supersistema de valores e de princípios que mostra ter as necessárias condições para compatibilizar plenamente o agir do Estado com a democracia substantiva, ou seja: não limitar a realização do o ideal democrático apenas à mera formalização da escolha de quem nos governa, mas, como observou JEAN RIVERO, ampliando-a à escolha de como queremos ser governados.

Finalmente, é ainda esse supersistema jurídico axio-principiológico que vem desmitificando o caráter exorbitante que insiste por inércia em remanescer na ação administrativa do Estado e desiludindo a velha lógica desigualitária da supremacia do interesse público, que sempre teimou em dificultar-lhe o controle. ${ }^{5}$

3 Cf. a respeito do tema revisional face às mutações do Direito Constitucional, a tese de OLIVIER BEAUD, La puissance de l'État, Paris, PUF, Coll. Léviathan, 1994.

4 Cf. FRANK MODERNE, Actualité des principes généraux du droit, RFDA, n 33, 1998, p. 518 , sobre a dimensão axiológica dos princípios jurídicos.

5 A esse respeito, a brilhante tese de STÉPHANE BRACONNIER, La jurisprudence de la Cour européenne des droits de l'homme et le droit administratif français (Bruylant, Bruxelles, 1997), na qual o Autor demonstra que a ação daquela Corte fez reverter a visão kelseniana do Direito, menos fundada na coerção e na força e mais respeitosa dos direitos do homem, entre os quais o de definir sempre e a qualquer tempo, pelas vias democráticas, o que venha a ser o interesse público, bem como o de negociar formas e modos de atendê-lo. Na mesma linha, no Brasil, o não menos excelente trabalho de HUMBERTO BERGMANN ÁVILA, Repensando o "Princípio da supremacia do interesse público sobre o particular", in O Direito Público em Tempos de Crise, Porto Alegre, Livraria do Advogado, 199, p. 99 e ss., fortemente travejado na doutrina tedesca contemporânea. 
Diante desses novos fenômenos, o mínimo que se pode fazer é enfrentá-los e estudá-los, jamais ignorá-los, pois só poderá ser a partir dessa nova leitura do Direito, feericamente iluminado pelos princípios, que se há de entender como e porque o pluralismo, enquanto fenômeno social, impulsionou o pluralismo político e com isso produziu as novas configurações do poder estatal, entre as quais a de independência orgânico-constitucional, objeto de especial consideração nos itens seguintes, um conceito que depassa do clássico esquema de tripartição de "Poderes" do Estado.

E aí está, portanto, exposta a linha metódica a ser seguida nestas notas, partindo do pluralismo social ao político e deste, ao jusconstitucional, para nele identificar e compreender os institutos contemporâneos de expressão do poder estatal.

\section{Condição plural do poder na sociedade e no estado democrático contemporâneos}

A aceitação da coexistência da multiplicidade de idéias e de valores nos grupos sociais conduz à questão da sua absorção ou rejeição. De um lado, preconceitos e xenofobias, quiçá reações instintivas de proteção, e, de outro lado, a curiosidade e a fantasia, que levam os grupos a dar um passo adiante em suas culturas, embatem-se milenarmente.

Se os grupos, em vez de ceder à tentação da segurança das homogeneidades hegemônicas, tolerarem e aceitarem essas desigualdades, absorvendo-as e aprendendo a com elas conviver, não apenas apesar delas, mas para serem por elas fertilizados, ascendem ao nível de sociedades pluralistas.

São essas, as sociedades que ganham dinamismo e se tornam aptas a transformarem-se em sociedades de confiança, como as denomina ALAIN PEYREFITTE ${ }^{6}$, as que apresentam as condições ótimas para o progresso auto-sustentado, independentemente da fertilidade dos campos ou das jazidas do subsolo, pois se fundam na maior riqueza das nações, que é a criatividade de pessoas livres.

O revolucionário reflexo do pluralismo social na política durante a segunda metade do século $\mathrm{XX}$ foi objeto de inúmeros estudos, como o clássico $O$ Processo de Governo, de ARTHUR F. BENTLEY, que introduziu a expressão sociedade pluralista para designar o todo social que comporta o convívio de grupos de indivíduos com interesses definidos e que desenvolvem uma atividade concertada para realizá-los, apontando essa riqueza na diversidade como um dos traços mais diferenciativos entre as sociedades do passado e as contemporâneas. ${ }^{7}$

Mas a principal diferença advinda com o pluralismo social não se limita à coexistência harmônica de vários grupos no conjunto da sociedade, mas está na peculiaridade de as pessoas se alinharem simultaneamente a vários grupos, conforme os seus interesses prevalecentes, o que desenha um caleidoscópio de situações sociais

6 ALAIN PEYREFITTE, La société de confiance, Paris, Ed. Odile Jacob, 1995.

7 ARTHUR F. BENTLEY, the Process of Government, Chicago University Press, 1908. 
em permanente mudança, tornando impossível identificar um status exclusivo ou definitivo para quem quer que seja.

Esta peculiaridade não escapou a pensadores contemporâneos, como Norberto BOBBIO $^{8}$ e MASSIMO SEVERO GIANNINI ${ }^{9}$, que a partir dela identificaram uma diáspora de centros de poder na sociedade civil e o surgimento do Estado Pluriclasse, como um novo tipo de organização política, relegando ao passado as tradicionais configurações dominantes, bem mais simples, em que os pólos de interesse e de poder social nele se refletiam em um centro hegemônico, no máximo a dois ou três, desenhando um quadro fechado e radical que facilmente levava a uma visão simplificadora mecanicista e dialética, como a da luta de classes pela hegemonia, e invocava apenas as básicas dicotomias freundianas entre amigo-inimigo e público e privado.

A respeito, já tive oportunidade de registrar que, por esse motivo, enquanto no passado o Direito era um instrumento dos interesses dos grupos hegemônicos e, a muito custo, mais recentemente, passou a refletir um certo equilíbrio entre os interesses dos grupos de maior expressão, na atualidade ele se tornou também pluralizado $^{10} \mathrm{e}$, por isso, de certo modo também mais imparcial, o que ocorreu na medida em que se impregnou dos inúmeros valores que ascendiam aos parlamentos, reproduzindo, no pluralismo político, o pluralismo social."

E de tal forma o pluralismo se tornou uma necessidade fundamental para a existência das sociedades complexas contemporâneas que passou a ser alçado às constituições, como um princípio fundamental, irradiando-se sobre todos os institutos políticos e jurídicos. ${ }^{12}$

Com isso, explícita ou implicitamente, é fora de dúvidas que o pluralismo se elenca hoje entre os principios que exprimem direitos fundamentais e que, por conseqüência, deve se cercar de todos os mecanismos protetivos que possam ser desenvolvidos pela ordem jurídica, seja no próprio texto constitucional, seja, por derivação, nos textos infraconstitucionais.

Recorde-se que na doutrina de PETER HÄBERLE, por mecanismos protetivos ou cláusulas protetoras desses direitos fundamentais, entre os quais, como se expôs,

8 NORBERTO BOBBIO, Dizionario di Política, Turim, UTET, 1983, $2^{\mathbf{a}}$ ed. Verbete pluralismo, VII, p. 820 .

9 MASSIMO SEVERO GIANNINI, Trattato di Diritto Amministrativo, Diretto da Giuseppe Santaniello, Pádua, CEDAM, Vol. $1^{\circ}, 1988$.

10 A referência é a meu Sociedade, Estado e Administração Pública, Rio de Janeiro, Topbooks, 1996, Cap. 5, em especial, p. 35.

11 A conotação do Direito à pluralização dos interesses está magistralmente descrita por MIGUEL REALE, em sua preciosa obra A Nova Fase do Direito Moderno, São Paulo, Saraiva, 1990, ao descrever a evolução da jurisprudência dogmática em direção à jurisprudência sociológica e, desta para a jurisprudência dos valores, na linha da revolucionária obra de Metodologia Jurídica de KARL LARENZ, Methodenlehre der Rechstswissenschaft, escrita em 1960 (Berlin, Göttingen, Heidelberg, Springer-Verlag), nela se destacando os Capítulos II (a jurisprudência dos conceitos) e V (da jurisprudência dos interesses à jurisprudência dos valores) e o genial encerramento deste Capítulo, em que o notável jurista enfrenta o problema da formação dos conceitos e do sistema.

12 No Brasil, a Constituição de 1988 incluiu o pluralismo político entre os princípios fundamentais em seu Título I, Art. $1^{\circ}$, inciso V. 
hoje há de necessariamente se destacar o pluralismo, com seus indissociáveis processos democráticos, que efetivamente o realizam, há de se entender, em última análise aqueles que garantam a fórmula do conteúdo essencial a eles referido, sejam "defensivos" ou "ofensivos", para usar ainda a linguagem do Mestre de Freiburg.

Não importa se tais cláusulas estejam positivadas como um preceito (como no art. $19^{\circ}$, inciso 2, da Lei Básica de Bonn, de que trata a sua célebre Freiburger Dissertation) ou apenas recebidas como um princípio, o que realmente importa é que possam cumprir, nas mãos do juiz, essa importantíssima função protetiva, que nada mais é que a realização jurídica da democracia substancial. ${ }^{13}$

Ora, entre esses mecanismos de proteção hão de se contar aqueles que instituam a independência de ação política de órgãos constitucionais destinados a assegurar a sociedade contra quaisquer mecanismos de fechamento de poder que a possam antagonizar.

Por mecanismos de fechamento de poder eram chamados, inicialmente, apenas os que repartiam total e completamente todos os poderes políticos entre os Estados existentes no planeta, o que implicava a absoluta identificação do Direito com o direito do Estado ${ }^{14}$.

Mais modernamente, o conceito de mecanismos de fechamento de poder se expandiu para abranger também quaisquer institutos que mantenham a reserva e a exclusividade do exercício dos poderes estatais concentradas apenas em alguns poucos órgãos da soberania, como, por exemplo e no caso, nos três Poderes clássicos.

De modo ainda mais amplo, tudo o que impeça ou limite a manifestação do pluralismo social em sede de poder político pode ser também considerado um mecanismo de fechamento, sempre que se trate de funções específicas de proteção de valores de uma sociedade em que o conjunto dos cidadãos se encontre em situação de paridade, quando não de superioridade em face do Estado, evoluindo de uma posição identificadora baseada no status para uma outra, própria da democracia substantiva, fundada no consensus. ${ }^{15}$

É por esse motivo que quaisquer institutos que representem um instrumento de proteçāo de direitos fundamentais constituem-se em avanços concretos no sentido da realização da democracia substantiva, como aquela que preserva a condição pluralista da sociedade e também do Estado.

Assim o são, colhendo um exemplo muito atual das agências reguladoras, os cometimentos específicos legalmente conferidos a essas autoridades administrativas independentes que, na expressão de BERNARD STIRN, além de desempenharem funções variadas que recobrem muitas vezes atribuições de natureza clássica, "de maneira mais inovadora, traduzem também, no domínio coberto por cada autoridade,

13 Cf. PETER HÄBERLE, La libertad fundamental en el Estado constitucional, Lima, PUC, 1997, trad. da tese doutoral Die Wesensgehaltgarantie des Art. 19 Abs. 2 Grundgesetz ( $3^{*} \mathrm{ed}$. ampliada), especialmente pp. 348 a 351.

14 Cf. A. PIZORUSSO, Sistemi giuridici comparati, Milão, Giuffrè Editore, 1998, p. 33 e ss.

15 Cf. ainda A. PIZORUSSO, op. cit., idem, ibidem. 
uma missão de regulação que se exerce por um magistério moral e por contactos com a opinião, formalizados notadamente através de um relacionamento público". ${ }^{16}$

É neste sentido que P. HÄBERLE entende o pluralismo como uma teoria que permite articular processualmente as relações entre sociedade e Estado e, com isso, unificar uma visão do bem comum que possa orientá-las ${ }^{17}$, o que permite descobrir uma nova visão a partir do intricado polissêmico implícito na palavra Estado ${ }^{18}$, que deixa no passado distante o Estado mentor (absolutista), em que os órgãos estatais monologam e definem o interesse público para a sociedade, que é o seu objeto; que ultrapassa também o Estado gendarme (liberal clássico), em que os órgãos do Estado dialogam com o indivíduo, mas se reservam o diktat sobre o que seja o interesse público; e chega, enfim, ao Estado democrático (democracia liberal, do modelo da Lei Básica de Bonn), em que os órgãos do Estado mantêm diálogos pluralizados e difundidos não apenas com os indivíduos, mas com todas as expressões grupais da sociedade, personalizadas ou não, para decidirem todos, em concerto, o interesse público e as políticas públicas que deverão ser dispostas para prossegui-lo. ${ }^{19}$

Parece claro que essa nova concepção pluralista do poder, que se difunde em todo um continuum sociedade-Estado, com seus centros constitucionais de imputação de exercício, sem cláusulas de fechamento cratológico, favorece o desenho de um Estado pluralista, que não é outro que o Estado Pluriclasse, com o bastismo de M. S. GIANNINI, em alguns países já existente e, em outros, in fieri: uma organização política talhada para este novo século que, mais do que qualquer das anteriores, estará apta a realizar, de modo institucional e permanente, pelo exercício da democracia, formal e material, a integração das diferenças.

\section{O poder estatal e sua distribuição orgânico-funcional na teoria constitucional}

O conceito de Estado, para a Ciência Política e para o Direito, não pode

16 BERNARD STIRN, Les sources constitutionnelles du droit administratif, Paris, Librairie Générale de Droit e de Jurisprudence, $3^{\mathrm{a}}$ ed., 1999, p. 127. Oportunamente, em passagem anterior, o autor deixa uma afirmação vigorosa sobre essas instituições que pode ser comodamente extrapolada para quaisquer das novas congêneres que exercem outras modalidades de competências independentes, exatamente na linha do que aqui se expõe: "l'institution d'une autorité administrative independente peut répresenter um élément de la protection constitutionenelle des droits fundamentaux" (p. 126).

17 P. HÄBERLE, Il diritti fondamentali nella società pluraliste e la Costitizione del pluralismo, STL, Laterza, 1995 (trad, it.).

18 Cf. L. FAVOREU, Droit Constitutionnel, précis Dalloz, Paris, 1998, p.52.

19 A Constituição italiana absorveu de modo particularmente a essa concepção pluralista do Estado, como se pode conferir na seguinte passagem do acatado Corso di Diritto Pubblico, de G. U. RESCIGNO, Bolonha, Zanicchelli, em sua 4" edição, de 1995, p. 14: "A tendência... é de conferir aos cidadãos que compõem a coletividade do povo um relevo juridico distinto daquele conferido à organização estatal", o que permite a existência de mecanismos de integração e de participação das coletividades ou "formações sociais" de todo tipo, como verdadeiros sujeitos do Direito Constitucional. 
prescindir das idéias de poder $^{20}$ e de organização, embora, também para a Sociologia e para a História, os inúmeros elementos que já foram pinçados em seu processo evolutivo institucional e que confluíram para cristalizá-lo, sejam inegavelmente relevantes.

Mas é do poder que se cogita quando o tema é o Estado, como energia da vontade dotada de algum tipo de capacidade de produzir efeitos desejados. Nesse sentido, estritamente cratológico, tem o poder a sua origem e expressão mínima e espontânea nos indivíduos, mas se acresce, se integra e se qualifica incessantemente em uma sociedade conformada por miríades de grupos secundários, que, como visto, detém, em diferentes graus, poderes próprios.

Está claro que quanto mais pluralista for a a sociedade, mais ricos os desdobramentos do poder social e a sedimentação do poder político, que dele deriva.

São essas expressões intermédias que são as matrizes das estruturas sociais e políticas de todos os tipos de complexidade e de expressão que portam a riquíssima diversidade do poder social, até que todas essas expressões se concentrem, perfazendo uma última transformação qualitativa, no Estado, dotando-o, então, do monopólio legítimo de todas as manifestações coercitivas e, com isso, alçando-o a mais complexa e acabada organização do poder político conhecida. ${ }^{21}$

Assim, o poder do Estado, entendido como aquele que as sociedades contemporâneas em ultima análise lhe cometem, é, por natureza, conceptualmente uno $e$ indivisivel: um axioma que se torna ainda mais nítido, quando se o concebe a partir da extraordinária integração jurídica das vontades que confluem para produzi-lo nos complexos processos seletivos desenvolvidos nas modernas democracias contemporâneas, o que se sintetiza nas duas características hoje positivadas na expressão Estado Democrático de Direito. ${ }^{22}$

Mas, se o poder do Estado é, por definição, uno e indivisível, o seu emprego aparece diversificadissimamente desdobrado, não prescindindo da possibilidade de expressar-se, igualmente, de muitos modos, para executar distintas funções, que se

20 Estudos sobre o fenômeno do poder são multidisciplinares e, para alguns, já conformam um ramo didaticamente autônomo, a Cratologia, que se vem estruturando com obras produzidas durante o século XX, entre os quais se pode mencionar: MAX WEBER, Wirtschaft und Gesellschafi, Tübingen, 1922; BERTRAN RUSSELL, Power, Londres, 1938; Bertrand de Jouvenel, Du Pouvoir, Genebra, 1947; H. D. LASSWFLL, Power and Personality, New York, 1948; H. D. LASSWELL e Alfred KAPLAN, Power and Society, New Haven, 1950; F. HUNTER., Community Power Structure, Chapel Hill, 1953; C. W. MILLS, The Power Elite, New York, 1956; R. A. DAHL, Who Governs?. New Haven, 1961; IDEM, Power, in International Encyclopedia of tbe Social Sciences, New York, 1968; C. J. FRIEDRICH, Man and His Government, New York, 1963; M. STOPPINO, Potere politico e Stato, Milano, 1968; IDEM, e verbete Potere, in Dizionario di Politica, dir. NORBERTO BOBBIO, $2^{2}$ ed., 1983, p. 864 ss. De minha própria autoria, mais recentemente, a Teoria do Poder (Sistema de Direito Político), publicado pela Editora Revista dos Tribunais, São Paulo, 1993.

21 Tal como o define, contemporaneamente GIUSEPPE DE VERGONTINI, in Diritto Costituzionale Comparato, Pádua, Edizione Cedam, 1999, p. 79: "La massima forma organizzata del potere político nelle società contemporânea viene definita come 'stato'.

22 Constituição da República Federativa do Brasil, art. $1^{\circ}$. 
apresentam assim como modos de expressão do poder estatal, cabendo às Constituiçōes a definição da expressão limitadora e condicionadora do emprego do poder estatal pelo instituto da competência.

Com este preciso sentido, a competência longe de ser um instituto que reparte o poder estatal, simplesmente autoriza determinados entes e órgãos, públicos $e$ privados, a exercitá-lo, de modo exclusivo, compartilhado ou em associação, daí porque PAUL LABAND já denominava a Constituição de Kompetenz von Kompetenz.

E como são também variadíssimos os modos possíveis de expressão do poder político, cada um deles se desdobra numa determinada função a ser exercida, de sorte que passam a existir inúmeras modalidades de funções políticas possíveis, numa lista em aberto que resiste a todos os esforços de categorização que as esgotem.

Assim, acrescem-se incessantemente às funções tradicionais constitucionalizadas - a normativa, a administrativa e a jurisdicional - novas outras funções constitucionais, como a para-normativa ${ }^{23}$, a para-administrativa ${ }^{24}$, a para-jurisdicional $^{25}$, a fiscalizadora ${ }^{26}$, a provocativa ${ }^{27}$, a participativa ${ }^{28}$, a defensiva ${ }^{29}$ (häberliana) e tantas outras mais que venham a ser caracterizadas na lei ou na doutrina juspublicista contemporâneas, como, no Brasil, a importante função consultiva vinculativa da advocacia pública ${ }^{30}$, e no Direito Comparado, outras funções como a de jurisdição constitucional (cortes constitucionais independentes) ou a de regulação monetária (bancos centrais indempendentes).

Por outro lado, em se tratando de funções públicas cometidas ao Estado, ainda que o sejam apenas em princípio, notadamente as que exigem o exercício do monopólio da coerção, neste caso, como condição para que logrem produzir suas pretendidas eficácias jurídicas, será necessário que se defina na ordem jurídica, a quem imputar o dever de exercê-las, o que torna necessário que se instituam órgãos aptos a desempenhá-las (melhor dito, portanto, que "poderes"), que podem ser, assim, conceituados genericamente como formas estruturais estáveis destinadas à expressão do poder estatal.

Ora, esses órgãos devem ser necessariamente criados e estruturados por normas jurídicas, com natureza de normas ônticas, que poderão ser constitucionais ou infraconstitucionais; será, porém, exclusivamente pela constitucionalização que em alguns deles se concentrarão certas específicas funções tidas como essenciais à existência do Estado, entre eles distribuindo do modo mais definido e minudente

23 Exemplo: art. 217, I, CF.

24 Exemplo: art. 177, § $2^{\circ}$, III.

25 Exemplo: art. $217, \S 1^{\circ} \mathrm{CF}$.

26 Exemplo: art. 129, II e III, CF.

27 Exemplo: art. 71, XI, CF.

28 Exemplo: art. 74, § $2^{\circ}, \mathrm{CF}$.

29 Exemplo: art. 103, I a IX, CF.

30 Instituída nos artigos 131, caput, e 132, caput, CF, que vinculam as autoridades consulentes ao teor do Parecer ou, alternativamente, a motivar juridicamente porque dele discordam. 
que for possível o exercício do Poder Público, daí o situarem-se no vértice da ordem jurídica.

Por esta razão, nessas funções e respectivos órgãos executores, encontra, o ilustre constitucionalista italiano Giuseppe de VERGOTTINI, a marca do Direito Público contemporâneo: um fenômeno juspolítico que denomina com precisão de "pluralidade dos centros constitucionais de imputação do poder "31.

Tão importante é hoje, para a teoria constitucional a estruturação do poder estatal, assim entendida como a distribuição de seu exercício por vários centros de imputação, todos e cada um, com suas múltiplas funções públicas a executar, que alguns autores, como o já referido J. J. GOMES CANOTILHO, a eles dedicam oportunos estudos voltados a uma melhor "compreensão material das estruturas organizatório-funcionais" do Estado, o que leva ao conceito de "constituição de direitos fundamentais, materialmente legitimada, e implica, ainda, "na articulação das normas de competência com a idéia de responsabilidade constitucional dos órgãos constitucionais (sobretudo dos órgãos de soberania) aos quais é confiada a prossecução autônoma de tarefas." 32

Este conceito, que aponta tantas diversificadas matrizes constitucionais para a conformação dos complexos orgânico-funcionais, que vêm sendo desenvolvidos pelo Estado em sua estruturação jurídica a partir das três revoluções fundantes do liberalismo, tem encontrado eco no pensamento teórico constitucionalista, desde as obras mais antigas às mais atuais deste século.

É o que se pode apreciar, como exemplo mais recente, em ENRICO SPAGNA MUSSO (1992), quando afirma "que a organização estatal está composta de uma série de órgãos, coerentemente predisposta à realização dos fins originários " $\mathrm{e}$, por isso deve ser, "o órgão, considerado na globalidade da função e da pessoa fisica que a intitula, a manifestar a vontade do Estado-pessoa ou do sujeito auxiliar inserido na organização pública da comunidade estatal", exatamente na mesma linha que, como exemplo mais remoto, SANTI ROMANO também já o afirmava quase meio século antes, em $1947 .{ }^{33}$

Outras vertentes, também contemporâneas, abalançam-se ainda a ir mais longe, ao reconhecerem, nesse desdobramento estrutural de entes e órgãos constitucionais, as novas formas ampliativas com que vem se apresentando, em suas mutações, o vetusto princípio da separação de poderes, ao distinguirem entre a separação horizontal, ou institucional, e a vertical, ou territorial, para na raiz delas encontrar $o$ mesmo propósito central, que é sempre o de contenção do poder, praticado em todas

31 Op. cit. p. 419.

32 J.J. GOMES CANOTILHO, Direito Constitucional, Coimbra, Ed. Almedina, 1991, $5^{\star}$ edição, transcrições da p. 689. Observe-se, porém, que, não obstante ofereça essa arguta observação genérica, o Autor se atém à tripartição rigorosamente adotada na Carta de seu País.

33 ENRICO SPAGNA MUSSO, Diritto Costituzionale, Pádua, Edizione Cedam, 1992, p. 60, com a nota (1) referida a SANTI ROMANO, Organi, in Frammenti di um dizionario giuridico, Milão, 1947, p. 145 e ss. A respeito, ainda de SANTI ROMANO, Nozione e natura degli organi costituzionali dello Stato, in Scritti Minori, Milão, 1949, I, p. 1 e ss. (n/grifo). 
as modalidades e submodalidades em que se possa apresentar, sempre que deva atuar para dividi-lo, limitá-lo, condicioná-lo, fiscalizá-lo ou controlá-lo.

É o tema de NUNO PIÇARRA ${ }^{34}$, de modo particular de KONRAD HESSE ${ }^{35}$ e o do próprio mencionado J. J. GOMES CANOTILHO, este último em sua obra já citada, quando acentua a existência do fenômeno do policentrismo institucional, que implica esse desdobramento de funções de natureza política. ${ }^{36}$

A identificação da matriz constitucional, ou seja, da instituição de determinado órgão na Constituição, como expressão de algum aspecto essencial de poder estatal, é também objeto de referência expressa de SPAGNA MUSSO que, diante das perplexidades que possa causar o pluralismo orgânico, abre um item especial em seu Direito Constitucional, sob o título Os órgãos e sujeitos constitucionais: critérios de identificação, no qual nos oferece algumas distinções relevantes para este estudo. ${ }^{37}$

Desde logo, sob aspecto meramente formal, qualquer órgão ou conjunto de órgãos será constitucional, desde que previsto no Texto Magno, o que, por ser um critério insuficiente, leva-nos forçosamente a considerar o aspecto material.

Este, por sua vez, abre-nos três alternativas, consoante o critério empregado.

Numa primeira alternativa, a distinção se faz entre órgãos constitucionais subordinantes e órgãos constitucionais subordinados ${ }^{38}$, como resultado do confronto entre as funções exercidas por cada um deles. ${ }^{39}$

$\mathrm{Na}$ segunda, a diferença se faz entre órgãos essenciais e não essenciais a um determinado ordenamento constitucional; assim entendidos como essenciais, os que desempenham funções que sejam expressões imediatas da soberania ou aquelas cujo exercício seja necessário à própria existência do Estado ${ }^{40}$, ou ambos. ${ }^{41}$

34 NUNO PIÇARRA, Ação dos Poderes como doutrina e princípio constitucional, Coimbra, Coimbra Editora, 1989, p. 265.

35 KONRAD HESSE afirma que em nenhuma parte da Constituição "a separação de poderes se encontra completamente realizada", e isso não só porque há interpenetração possível entre poderes como porque como podem existir "órgãos especiais" que inegavelmente detêm poder estatal mas não se enquadram em esquemas rígidos, como é o caso do Tribunal Constitucional Federal (Das Bundesverfassungsgericht), um Tribunal da Federação, autônomo e independente, inclusive financeira e orçamentariamente (v. Grundzüge des Verfassungsgerechts der Bundesrepublik Deutschland, Heidelberg, C.F. Muller Verlag, Hüthig GmbH, 1995, $20^{\star}$ edição, tradução brasileira de LUIS AFONSO HECK, Porto Alegre, Sergio Antonio Fabris Editor, 1998, pp. 365 a 367 e 487 a 489).

35 J. J. GOMES CANOTILHO, op. cit., p. 711.

37 ENRICO SPAGNA MUSSO, op.cit., pp. 63 a 65.

38 V. SPAGNA MUSSO, op, cit. p. 63.

39 Sob este critério, embora de assento constitucional e, portanto, atendendo ao requisito formal, o Colégio Pedro II (art. 242, CF), por exemplo, não recebe na Carta Políica qualquer função que possa sequer ser confrontada, enquanto que, em outro exemplo de órgão de menção constitucional, ao Ministério Público (art. 127, CF) são cometidas várias funções (art. 129) que podem ser confrontadas com as de outros órgãos ou complexos orgânicos constitucionais.

40 V. SPAGNA MUSSO, idem, ibidem.

41 Sob este outro critério, embora de assento constitucional, as Guardas Municipais (art. 144, § $8^{\circ}, \mathrm{CF}$ ) nem desempenham funções imediatas da soberania nem são indispensáveis à existência do 
Numa terceira e mais sutil classificação, SPAGNA MUSSO introduz uma distinção quanto aos órgãos portadores ou garantidores dos valores político-constitucionais do Estado ${ }^{42}$, ou seja, aqueles que apresentem uma conexão com as formas e regimes de governo adotados, abrangendo, neste caso, não apenas órgãos do Estado como até órgãos da sociedade que desempenhem funções dessa natureza. ${ }^{43}$

É sobre esses órgãos portadores ou garantidores dos valores político-constitucionais do Estado que J.J. GOMES CANOTILHO se refere como "órgãos constitucionais de soberania, que, além de derivarem imediatamente da Constituição, destacam-se por serem coessenciais à caracterização da forma de governo constitucionalmente instituída." 44

Até aí descrevem-se generalidades teoréticas e sua pertinente doutrina, mas o trabalho de identificação concreta desses órgãos constitucionais exercentes de parcelas da soberania só pode resultar do exame casuístico das Cartas Políticas, nelas pesquisando-se a natureza das funções por eles desempenhadas.

\section{O caso da natureza e taxinomia juspolíticas dos tribunais de contas}

Chega-se, então, ao exame pretendido nestas notas, sobre a natureza jurídica e a taxinomia dos Tribunais de Contas no sistema constitucional brasileiro.

Ora, a partir do Tribunal de Contas da União, que, no Brasil, é padrão para os órgãos congêneres estaduais e municipais (art. 75), pode-se observar que essas instituições satisfazem concomitantemente a todos os critérios acima expostos, que as identificam e as distinguem no ordenamento jurídico brasileiro entre as estruturas políticas mais importantes de expressão do poder estatal, desempenhando diversas funções de proteção de direitos fundamentais de sede constitucional.

Com efeito, desde logo, a sua mera previsão na Carta já o faz, formalmente, um órgão de matriz constitucional, mas, do mesmo modo, materialmente, ostenta todas as condições requeridas na classificação de SPAGNA MUSSO, a saber.

Primeiro, materialmente, como órgão constitucional subordinante, uma vez que lhe são cometidas doze funções constitucionais (art $71 \mathrm{e} \S 2^{\circ}$ ) que permitem evidenciar relações em face às funções de outros órgãos ou conjuntos orgânicos do Estado.

Segundo, materialmente, como órgão constitucional essencial, por desempenhar funções políticas, assim entendidas as que são expressões imediatas da soberania (art. 73, I, c/c art. 70, caput), uma vez que:

Estado, aliás nem mesmo à de um Município, enquanto que, no extremo oposto, as Forças Armadas (art. 142, CF) desempenham funções que são expressões da soberania (defesa da Pátria) e essenciais à existência do Estado (garantia dos poderes constitucionais, da lei e da ordem).

42 V. SPAGNA MUSSO, idem, pp. 64 e 65.

43 Em exemplos dados pelo próprio autor italiano, "em um Estado de democracia pluralista devem ser qualificados como sujeitos constitucionais os partidos... e se o Estado tem estrutura federal, seus Estados-membros..." Idem, ibidem.

44 J.J. Gomes Canotilho, op. cit., p. 709 (n/grifo). 
1) - aprecia a legitimidade e não apenas a legalidade das contas (art. 71 , I e II);

2) - julga as contas de administradores públicos, com exceção das contas do Chefe do Poder Executivo (art. 71, II);

3) - fiscaliza aplicações de recursos repassados pela União aos demais entes da Federação (art. 71, VI);

4) - aplica sançōes pecuniárias a agentes financeiros (art. 71 VIII);

5) - susta a execução de atos financeiramente impugnados de todos os Poderes (art. 71, X); e

6) - decide a respeito de contratos se o Poder Legislativo não tomar medidas a respeito depois de provocado (art. $71, \S \S 1^{\circ} \mathrm{e} 2^{\circ}$ ).

Terceiro, materialmente, como órgão garantidor dos valores político-constitucionais do Estado Democrático de Direito, ou seja, porque exerce funções indispensáveis ao funcionamento dos princípios republicano e democrático, no tocante a um dos mais delicados aspectos de qualquer governo, que é, desde a Magna Carta, a gestão fiscal: a disposição político-administrativa dos recursos retirados impositivamente dos contribuintes. ${ }^{45}$

Em suma, se é certo que se pode afirmar, com BISCARETTI DI RUFFIA, que a repartição de funções dá origem à teoria da divisão dos poderes,${ }^{46}$ também procede asserir-se que, em termos de expressão do Poder Estatal, hoje prevalece o policentrismo institucional, a que se refere J.J. GOMES CANOTILHO.

Com efeito, a estruturação do poder do Estado é historicamente dinâmica, pois segue a linha da contenção de monopólios e oligopólios do poder político, como uma providencial garantia da sociedade contra os males que eles semearam em um passado ainda muito próximo.

Assim, o processo organizativo do poder está longe de se ter esgotado no moderno constitucionalismo, e vai prosseguindo, a destacar novas funções específicas, que passam a ser desempenhadas por órgãos, mas que não mais se incluem nos três complexos orgânicos que são denominados, por metonímia tradicional, de $\mathrm{Po}$ deres, porque exercem o que eram antes as únicas, mas hoje restam apenas como as mais importantes segmentações do Poder do Estado (ou os "Poderes da União", como está no art. $\left.2^{\circ}, \mathrm{CF}\right)$.

45 Embora a definição das finanças públicas, vis-ăa-vis às finanças privadas, seja muito antiga, remontando aos arcanos conceitos dos tesouros reais, os primórdios de um Direito Público Financeiro só começaram a despontar com o aparecimento das primeiras restrições jurídicas impostas aos monarcas para disporem arbitrariamente dos seus respectivos erários.

Essa submissão era uma primeira conquista de um longo processo de racionalização e juridicização das finanças públicas, que se desdobra, para comodidade didática, em quatro fases evolutivas distintas e denominadas, sucessivamente, de regaliana, liberal, intervencionista e democrática, que se iniciou quando da organização dos primeiros Estados modernos, existindo consenso sobre o pioneirismo histórico da Inglaterra.

46 PAOLO BISCARETTI DI RUFFIA, Direito Constitucional. (Instituições de Direito Público), São Paulo. Ed. Revista dos Tribunais, 1884, p. 160. 
Os Tribunais de Contas são, assim, um nítido exemplo desse fenômeno, no contexto da ordem jurídica brasileira, mas, do mesmo modo, também o são as Funções Essenciais à Justiça, com ênfase no complexo orgânico do Ministério Público, a que se acrescem ainda os Conselhos Profissionais, depois de sua recente transformação, um rol que pode ser ainda ampliado, como já ocorre em outros países, com a inclusão constitucional de novos órgãos aos quais se cometam funções estatais, dotando-lhes de autonomia com vistas ao aprimoramento do controle e da democracia, tais como um Ombudsman ou uma Agência constitucionalmente independente, em alguns casos, os Bancos Centrais.

"Esta evolução", conclui NUNO PIÇARRA, para bem encerrar com sua arguta síntese o que aqui se procurou elucidar, "está, aliás, em consonância com a progressiva transição de um método abstrato-dedutivo para um método normativo-concreto na abordagem e no tratamento dogmático do princípio da separação dos poderes. Ele tende hoje a construir-se a partir da ordenação de competências constitucionais concreta." ${ }^{47}$ (n/grifo).

\section{Exposição sobre a natureza e taxinomia juspolíticas dos tribunais de contas}

A preocupação histórica com a atividade financeira pública, o controle da entrada e saída dos recursos dos Erários, remonta, para alguns, à Grécia Clássica; outros entendem que o processo só viria a se afirmar no Século XIV, com a afetação obrigatória dos novos impostos aos gastos admitidos pelo Parlamento da Inglaterra, o que apenas no Século XVI voltaria a se estender, com a Petição de Direitos, para tornar obrigatória a autorização afetatória para todos os impostos.

Mas a história dos orçamentos começaria ainda mais tarde, em 1688, entre as novas instituições trazidas pela gloriosa revolução liberal, com seu histórico documento, o Bill of Rights, imposto ao Rei pelo movimento vitorioso, em que se passava a exigir, não apenas o consentimento do Parlamento para lançar quaisquer impostos (receita), como a produção anual de um demonstrativo real de como os impostos seriam empregados (despesa).

Mas se a preocupação com as finanças públicas é muito antiga e a prática do orçamento público só surgiu no Renascimento, o controle público institucional financeiro-orçamentário através de orgãos especializados, os Tribunais de Contas é uma criação relativamente recente, do século XIX, tendo sido adotado, sucessivamente, a partir do modelo napoleônico francês, de 1807, sob várias modalidades, em vários países europeus, como a Itália (1807, remodelado em 1849), a Bélgica (1841), a Prússia (1876), e chegado ao Brasil republicano, como é ressabido, por influência de Ruy Barbosa, em 1890, institucionalizado pelo Decreto-Lei n ${ }^{\circ} 966-\mathrm{A}$, de 7 de novembro de 1890.

Esse breve apanhado histórico foi exposto apenas para pôr em relevo, simultaneamente, em termos substantivos, a marca liberal impressa ao controle da gestão 
financeira pública e, em termos formais, a autonomia institucional com que foram criados em sua maioria, fora das estruturas burocráticas.

São duas assinaladas características históricas que acompanham a instituição e que assumem hoje definitiva importância no Estado Democrático de Direito, na medida em que já se revelam plenamente amadurecidas, respectivamente, para a realização do controle democrático da gestão financeiro-orçamentária e para a sua independência orgânico-funcional.

A versão institucional brasileira do Tribunal de Contas passou por várias mudanças, nas sucessivas Constituições republicanas, que o foram aperfeiçoando no correr do século XX, tendo recebido, indubitavelmente, a sua forma mais aperfeiçoada, na Constituição de 1988.

Assim. o assento constitucional concernente aos existentes Tribunais de Contas, da União, dos Estados, do Distrito Federal e dos Municípios do Rio de Janeiro e de São Paulo, bem como, ainda nos Estados, dos Conselhos de Contas dos Municípios, está na Seção IX, do Capítulo I, do Título IV (Da Organização dos Poderes), dos arts. 70 a 75 , nos quais, esquematicamente, se institui:

1 - sua organização (art. 73 e 75);

2 - sua independência administrativa, financeira e orçamentária, tal como se a assegura aos Tribunais do Poder Judiciário (art.73, caput, c/c art. 96, I, e 75); e 3 - suas funções (art. $71,74, \S \S 1^{\circ}$ e $2^{\circ}$, e 75 ).

A análise sistemática desses dispositivos é que fornece a chave para determinar a natureza jurídica e a taxinomia constitucional dos tribunais e conselhos acima relacionados, como aqui se pretende expor.

Quanto à natureza da organização, tem-se órgãos colegiados, dotados das atribuições autonômicas dos tribunais do Judiciário e sem qualquer relação de hierarquia ou de dependência em relação aos Poderes e a quaisquer outros órgãos constitucionais.

Quanto à natureza das funções, não mais importa aqui retornar à velha questão de se determinar se o julgamento de contas dos administradores públicos seria ou não uma função de natureza jurisdicional ${ }^{18}$, um tema, aliás, já suficientemente dirimido pela doutrina, como se pode comprovar na primorosa monografia de ODETE MEDAUAR, Controle da Administração Pública ${ }^{49}$.

Com efeito, o problema juspolítico da sua natureza jurídica, bem como de sua taxinomia, nada tem a ver diretamente com o mecanismo clássico da tripartição de Poderes, ou seja: a solução não está no enquadrar-se um determinado órgão independente em qualquer um dos três Poderes orgânicos tradicionais.

48 Esta posição é defendida entre nós por JARBAS MARANHÃO, AECIO MENUCCI, CARLOS S.DE BARROS JÚNIOR E SEABRA FAGUNDES.

49 ODETE MEDAUAR, Controle da Administração Pública, São Paulo, Revista dos Tribunais, 1993, p. 141 e 142. 
Essa questão está superada, necessitando ser equacionada diferentemente, pois se trata, agora, de trabalhar, na linha das soluções contemporâneas, à luz dos subsídios doutrinários expostos, com o conceito de policentrismo institucional, para usar a feliz expressão de CANOTILHO, para perquirir, nessa linha, a natureza das funções exercidas pelas cortes de contas.

É, portanto, pelo exame casuístico das funções atribuídas, conforme a orientação de SPAGNA MUSSO, ao se referir àqueles órgãos que no seu desempenho portem ou garantam valores político-constitucionais do Estado ${ }^{50}$, que se caracterizará, em última análise, a natureza jurídica desses tribunais e conselhos.

Assim é que, na análise que a seguir se procederá sob essa orientação, das funções constitucionais atribuídas ao Tribunal e Contas, nos arts. $71,74, \S \S 1^{\circ}$ e $2^{\circ}$, e 75 da Constituição, distinguir-se-ão dois tipos de atuação de controle: o técnico e o político.

Do exame pontual do que está explícita ou implicitamente nos preceitos indicados defluirá um juízo amplo e seguro sobre a natureza de sua atuação. Este é o texto do caput:

“Art. 71. O controle externo, a cargo do Congresso Nacional, será exercido com o auxílio do Tribunal de Contas da União, ao qual compete:"

Como se pode observar, com a determinação de que o controle externo será exercido com o auxílio do Tribunal de Contas, já seria bastante esse caput para afastar a hipótese de existência de uma eventual margem discricionária para o Congresso Nacional vir a optar se aceita ou não a coadjuvação: muito ao contrário, o preceito torna inequivocamente obrigatória a cooperação do Tribunal de Contas.

Ora, se o Poder Legislativo, que é o poder político par excellence, como órgão máximo de representação democrática, se deve valer necessariamente da atuação coadjutória do Tribunal de Contas, duas conclusões parciais podem ser retiradas.

A primeira, uma conclusão de que a Constituição instituiu uma distinção estrutural de cunho político entre o Poder Legislativo e o Tribunal de Contas; e o fez, não só por estar a mencioná-los separadamente, o que seria um dado puramente formal, como, e principalmente, por que estabeleceu entre ambos uma relação, que não sendo paritária nem, tampouco, de hierarquia ou de subordinação, só pode ser de cooperação, o que claramente se expressa na voz auxílio.

Segundo, como o caput é genérico, e se refere irrestritamente a controle externo, deve-se concluir, a priori, que essa cooperação foi preconizada também genericamente, o que vale dizer que, embora não tendo toda a amplitude prevista no art. 49, IX e X, da Constituição, e de aparecer limitada por um rol de atribuições específicas, que a seguir serão examinadas (muito embora, como se verá, comporte também certas atuações discricionárias), é inegável que a função de cooperação compartilha a mesma natureza política de controle que é exercida pelo órgão assistido.

Torna-se, agora, muito mais fácil, com esses adminículos, examinar o elenco de atribuições específicas que se seguirá, para nelas distinguir pontualmente quando 
a cooperação é apenas técnica, ou seja, quando o Tribunal de Contas atua como especialista no processamento da legalidade e da economicidade dos dados contábeis financeiros, orçamentários e patrimoniais ${ }^{51} \mathrm{e}$, assim, despido do caráter decisório de órgão da soberania, ou quando a sua cooperação assume natureza política, ou seja, quando o Tribunal atua na avaliação da legitimidade dos dados operacionais da administração financeiro-orçamentária, neste caso, mesmo sem definitividade ${ }^{52}, e m i$ tindo decisões revestidas do típico caráter dos órgãos da soberania.

Com efeito, o controle da gestão financeira pública no Estado Democrático de Direito não mais apresenta a natureza de subordinação e de subalternidade prevalecentes no período anterior, em que predominavam os modelos positivistas de Estado hipertrofiado, caracterizadores da época das finanças públicas intervencionistas, vivida sob o signo das grandes confrontações bélicas e ideológicas do século passado.

O ressurgimento das finanças públicas liberais voltadas aos interesses das sociedades, tal como elas os expressam, e, por isso submetidas à legitimidade da ação fiscal, deu-se no segundo Pós-Guerra e foi, assim, um fruto da paz, propiciado pela explosão das comunicações, que despertou uma renovada consciência cidadã e, com ela, os reclamos por afirmação que estavam abafados por quase um século.

Assim é que, com as mudanças da sociedade, mudava o Estado e, é claro, a administração pública.

Nesse novo quadro político, as finanças públicas, por serem um instrumento da administração pública, não mais poderiam ficar atreladas ao alvedrio dos Executivos e confinadas ao horizonte legitimatório extremamente curto em que eles se movem.

Era necessário voltar à pureza do referencial legislativo para alongar os horizontes de ação e, sobretudo, para estabelecer os fundamentos de legitimidade de longo prazo para as políticas públicas, providências indispensáveis para evitar as inflações crônicas e os endividamentos em cascata, que haviam sido os tormentos de tantos países.

Mas não bastava alongar os termos de referência administrativos com robustas afirmações de democracia substantiva: as demandas passavam a ter uma ancoragem mais profunda na ética, crescendo as exigências, não apenas de probidade como, inovadoramente, de qualidade na gestão da coisa pública, enriquecendo os conceitos correspondentes de controle de gestão financeiro-orçamentária, tal como se nos vem hoje legislado na Lei Complementar $\mathrm{n}^{\circ} 101$, de 4 de maio de 2000.

Com isso, tanto os comportamentos ofensivos à moralidade administrativa, como os incompatíveis com a eficiência administrativa, deixavam de ser remotos e vagos referenciais idealizados, mas despidos de obrigatoriedade, para se tornarem

51 São atribuiçōes conceituais do controle interno e do controle externo, assim relacionadas no art. 70, CF.

52 A definitividade não é atributo da atividade política, como se pode constatar não só na decisão cautelar, que pode ser modificada a qualquer tempo, como nas decisões sujeitas a recursos de todo gênero. 
referenciais positivados nas Constituições e nas leis, ambos rigorosamente sancionados, podendo ser levantados por multiplicadas instâncias controladoras.

Como tão bem nos explica RICARDO LOBO TORRES, sopra um novo hausto a permear a moral no Direito: "Na moderna democracia deliberativa o direito não se justifica (mais) a si próprio, senão que vai buscar fora de si, nos princípios morais, a sua razão de ser" ${ }^{53}$; ao que se pode, na mesma linha, acrescentar que a administração pública não se justifica, tampouco, pela mera eficácia com que atua, senão que deve buscar nas demandas reais da sociedade a que serve, a eficiência como razão de ser, pois esta é a resposta certa aos reclamos de legitimidade.

Desse modo alterada, a administração pública, enquanto função de um Estado subsidiário à sociedade, e não mais um conjunto de prerrogativas de um Estado tutor, passa então a ser submetida não mais somente ao tradicional crivo da legalidade, em que se demandava apenas a qualidade da eficácia, mas, ainda em acréscimo, aos da licitude e da legitimidade, justificando-se, respectivamente, perante as demandas, pela moralidade e pela eficiência administrativas, que despontam como novos princípios constitucionais.

Nesse renovado quadro, a gestão fiscal pública se vai tornando, cada vez mais intensamente, a necessária, obrigatória e transparente expressão financeira de politicas públicas legítimas, portanto, consentidas e subsidiárias, que devem, por isso, prever riscos fiscais, e no desempenho das quais, os agentes políticos e administrativos devem atuar com qualidades de prudência, responsabilidade e responsividade, tudo incorporado à ordem jurídica do País pela Lei Complementar $n^{\circ}$ 101/2000, já referida. Abrem-se, assim, para todos os órgãos de contas, amplas e fascinantes fronteiras no novo e delicado, mas superiormente concebido, controle fiscal da legitimidade, que se inaugura.

Por derradeiro, e na mesma direção, que é a de realização da legitimidade democrática nas finanças públicas, o parágrafo único, ao estender a atuação do Tribunal de Contas a toda a sociedade (pessoas físicas e pessoas privadas em geral), já seria um preceito suficientemente incisivo para desqualificar qualquer limitação exegética que ainda o pretendesse reduzir a uma atuação meramente interna e subordinada, de controle de legalidade.

Segue-se, sob essa orientação conceptual contemporânea, que é uma autêntica marca juspolítica de nossos dias, o exame pontual das atribuições que vêm expressas nos incisos e nos demais preceitos que explicitam funções das cortes de contas.

I. apreciar as contas prestadas anualmente pelo Presidente da República, mediante parecer prévio, que deverá ser elaborado em sessenta dias a contar de seu recebimento.

53 RICARDO LOBO TORRES, O principio da transparência no Direito Financeiro, original em suelto, enviado por nímia cortesia, a constar da coletânea, por ele organizada para a Revista de Direito da Associação dos Procuradores do Novo Estado do Rio de Janeiro, no prelo quando se elaborou este Parecer (a expressão em itálico é uma ênfase deste Parecerista). 
Este inciso também se agrega como poderoso reforço da interpretação aqui preconizada, pois nele se institui uma claríssima competência autônoma do Tribunal de Contas para apreciar não apenas a legalidade e a economicidade das contas do Chefe do Poder Executivo, como se estende à sua legitimidade, abrindo-lhe uma extensa margem discricionária para emitir um parecer, um ato fundamentado que não poderá ser modificado pelo Poder Legislativo, mas apenas considerado ou não por ocasião do julgamento parlamentar dessas contas (art. 49, IX, CF), tratando-se, portanto, de uma cooperação de natureza mista: parte técnica, parte política, como a seguir se aponta.

II. julgar as contas dos administradores e demais responsáveis por dinheiros, bens e valores públicos da administração direta e indireta, incluidas as fundações e sociedades instituídas e mantidas pelo poder público federal, e as contas daqueles que derem causa a perda, extravio ou outra irregularidade de que resulte prejuízo ao erário público;

Novamente, neste segundo inciso, se está caracterizando uma atuação combinada, técnica e politica, esta, não apenas pela atribuição de examinar a legitimidade das contas, como pela previsão de atuar autonomamente, decidindo apenas por si (julgar as contas) e não mais em cooperação com o Poder Legislativo.

III. apreciar, para fins de registro, a legalidade dos atos de admissão de pessoal, a qualquer título, na administração direta e indireta, incluídas as fundações instituidas e mantidas pelo poder público, excetuadas as nomeações para cargo de provimento em comissão, bem como a das concessões de aposentadorias, reformas e pensões, ressalvadas as melhorias posteriores que não alterem o fundamento legal do ato concessório;

Atribuição registrária, das mais antigas das Cortes de Contas, de natureza técnica.

IV. realizar, por iniciativa própria, da Câmara dos Deputados, do Senado Federal, de comissão técnica ou de inquérito, inspeções e auditorias de natureza contábil, financeira, orçamentária, operacional e patrimonial, nas unidades administrativas dos Poderes Legislativo, Executivo e judiciário, $e$ demais entidades referidas no inciso II; (n/ grifo)

A expressão iniciativa própria já diz tudo, até porque as inspeções e auditorias podem ser realizadas no próprio Poder Legislativo, o que não poderia ocorrer se partisse de um órgão subordinado. Este inciso é, por isso, relevante para definir-lhe uma função política e, a partir dela, fixar-se a taxinomia dos Tribunais de Contas.

V. fiscalizar as contas nacionais das empresas supranacionais de cujo capital social a União participe, de forma direta ou indireta, nos termos do tratado constitutivo: 
Aqui se prevê outra atividade técnica.

VI. fiscalizar a aplicação de quaisquer recursos repassados pela União, mediante convênio, acordo, ajuste ou outros instrumentos congêneres, a Estado, ao Distrito Federal ou a Município;

Como é necessário interpretar as cláusulas dos atos complexos mencionados, o que inclui avaliação de legitimidade, esta atividade de controle é também de natureza mista: técnica e política.

VII. prestar as informações solicitadas pelo Congresso Nacional, por qualquer de suas Casas, ou por qualquer das respectivas comissões, sobre a fiscalização contábil, financeira, orçamentária, operacional e patrimonial $e$ sobre resultados de auditorias e inspeções realizadas.

A prestação de informações ao poder Legislativo é uma característica indissociável do regime democrático, mas resulta em mero ato declaratório.

VIII. aplicar aos responsáveis, em caso de ilegalidade de despesa ou irregularidade de contas, as sanções previstas em lei, que estabelecerá, entre outras cominações, multa proporcional ao dano causado ao erário; (n/grifo)

Novamente, neste inciso, caracteriza-se uma atuação autônoma do Tribunal de Contas, ao decidir apenas por si (aplicar sanções) e aqui, observe-se, não mais em cooperação com o Poder Legislativo.

IX. assinar prazo para que o órgão ou entidade adote as providências necessárias ao exato cumprimento da lei, se verificada ilegalidade;

Também aqui se trata de atuação vinculada por motivo de ilegalidade.

$X$. sustar, se não atendido, a execução do ato impugnado, comunicando a decisão à Câmara dos Deputados e ao Senado Federal;

O ato de sustação, embora neste caso não seja definitivo, é uma decisão de natureza política exercida pelo Tribunal de Contas, em que se manifesta a soberania do Estado ao incidir sobre atividades financeira públicas de qualquer outro órgão ou entidade.

XI. representar ao Poder competente sobre irregularidades ou abusos apurados.

No caso de não serem sanções aplicáveis pelo próprio Tribunal de Contas, essa representação será mandamental e de caráter técnico. 
$\S 1^{\circ}$. No caso de contrato, o ato de sustação será adotado diretamente pelo Congresso Nacional, que solicitará, e imediato ao Poder Executivo as medidas cabiveis.

$\S 2^{\circ}$. Se o Congresso Nacional ou o Poder Executivo, no prazo de noventa dias, não efetivar as medidas previstas no parágrafo anterior, o Tribunal decidirá a respeito. (n/grifo)

Com esses dispositivos, inverte-se a previsão acima, do inciso $\mathrm{X}$, uma vez que a iniciativa da sustação fica reservada ao Poder Legislativo, só se devolvendo o poder decisório ao Tribunal se ocorrer omissão, do Congresso Nacional ou do Poder Executivo, o que o reinvestirá constitucionalmente no exercício de uma atividade de natureza política, tipicamente de exercício de poderes da soberania em face dos demais Poderes referidos.

Estranhamente, essa previsão de sustação de contratos não se aplica ao Poder Judiciário; isso, por falta de expressa previsão constitucional, que é sempre necessária quando se trata de interferências entre Poderes. ${ }^{54}$

Art. $74 \ldots$

$\S 1^{\circ}$. Os responsáveis pelo controle interno, ao tomarem conhecimento de qualquer irregularidade ou ilegalidade, dela darão ciência ao Tribunal de contas da União, sob pena de responsabilidade solidária.

$\S 2^{\circ}$. Qualquer cidadão, partido político, associação ou sindicato é parte legítima para, na forma da lei, denunciar irregularidades ou ilegalidades perante o Tribunal de Contas da União.

Esses dois parágrafos atribuem novas e especialíssimas funções aos Tribunais de Contas; o primeiro deles, determinando que os responsáveis pela gestão fiscal thes dêem ciência de irregularidades ou ilegalidade, e o segundo, facultando aos nele legitimados, de modo amplíssimo, a provocar-lhe a ação fiscalizatória autônoma.

No segundo caso, fica novamente e sobremodo patenteado que a ordem jurídica brasileira tem nos Tribunais de Contas um instrumento da cidadania ativa, o que os torna, também por isso, indispensáveis ao bom funcionamento do regime democrático.

Art. 75. As normas estabelecidas nesta Seção aplicam-se, no que couber, à organização, composição e fiscalização dos Tribunais de Contas dos Estados, e do Distrito federal, bem como dos Tribunais e Conselhos de Contas dos Municípios.

Aqui se estendem a todos os órgãos congêneres da federação as normas prescritas para o Tribunal de Contas da União, compreendida na expressão fiscalização,

54 Nesta linha, do autor deste Parecer, o artigo Interferências entre Poderes do Estado. Fricçōes entre o Executivo e o Legislativo na Constituição de 1988. In Boletim de Direito Administrativo, Ano VI, n 6, junho de 1990, pp. 331 a 344. 
por um tropo de linguagem, todas as funções acima examinadas, de modo que se pode afirmar que a natureza jurídica e a taxinomia de todos aqueles órgãos de contas são constitucionalmente análogas.

Essa resenha de funções examinadas, técnicas e políticas, demonstram à saciedade o hibridismo funcional do Tribunal de Contas na organização constitucional brasileira e, por isso, o caracterizam como um órgão autônomo da estrutura constitucional do Estado, compartilhando dos poderes inerentes à soberania.

E não se alegue, palidamente, em contrário, a falácia que equivocadamente se tem apregoado, sustentada apenas numa pobre exegese filológica, a de que o Tribunal de Contas seria um órgão auxiliar do Poder Legislativo e, por isso, dele parte integrante, porquanto essa voz auxilio não apresenta qualquer sentido de subordinação, como foi demonstrado, mas de cooperação entre entes independentes.

Fica, a respeito, como conclusão parcial, esta que se faz com plena harmonia da boa doutrina, encontrada na lição de ODETE MEDAUAR:

"A Constituição Federal, em artigo algum, utiliza a expressão "órgão auxiliar"; dispõe que o controle extermo do Congresso Nacional será exercido com o auxílio do Tribunal de Contas; a sua função, portanto, é de exercer o controle financeiro e orçamentário da Administração em auxilio do poder responsável, em última instância, por essa fiscalização."

E arremata a brilhante administrativista:

“Tendo em vista que a própria Constituição assegura ao Tribunal de Contas as mesmas garantias de independência do Poder Judiciário, impossivel considerá-lo subordinado ao Legislativo ou inserido na estrutura do Legislativo.(n/grifo) Se a sua função é de atuar em auxílio do Poder Legislativo. Sua natureza, em razão das próprias normas da Constituição, é a de órgão independente, desvinculado da estrutura de qualquer dos três poderes. A nosso ver, por conseguinte, o Tribunal de Contas configura instituição estatal independente (grifo da Autora)." 55

No mesmo sentido, a doutrina tradicional de CELSO ANTONIO BANDEIRA DE MELLO, quando assevera que " $O$ ser órgão auxiliar não configura, por si só, $a$ integração em um dado conjunto orgânico... O Tribunal de Contas, em verdade, não é subordinado ao Poder Legislativo, nem está sob a tutela dele." ${ }^{56}$ (n/grifo).

Afinal, valha o aditamento, um "órgão auxiliar", se devesse ser entendido como

55 ODETTE MEDAUAR, Controle da Administração Pública. São Paulo, Revista dos Tribunais, 1993, pp. 140 e 141.

56 CELSO ANTONIO BANDEIRA DE MELLO, O tribunal de Contas e sua Jurisdição, Revista do Tribunal de Contas do Estado do Rio de Janeiro, 1982, p. 122. 
subalterno ou integrado, não poderia apreciar as contas da Mesa do Poder Legislativo, como tem reiteradamente reconhecido o Supremo Tribunal federal. ${ }^{57}$

Mas o argumento final e definitivo de que a expressão "com auxílio de" não implica qualquer integração do órgão de contas competente ao Poder Legislativo, é a própria Constituição que o traz, patente e extreme de dúvidas, no artigo $31, \S$ $1^{\circ}$, ao referir-se às três modalidades de auxílio de que se poderão valer as Câmaras de Vereadores, que serão, indiferentemente, conforme a respectiva estrutura política, a do Estado-membro (com duas possibilidades: 1. o Tribunal de Contas do Estado ou 2. o Conselho ou Tribunal de Contas dos Municípios) ou a do próprio Município (3. o Tribunal de Contas do Município).

Resulta meridianamente claro que, para o exercício dessa função constitucional de auxiliar no controle externo de contas públicas, não é necessário que o órgão cooperador pertença à estrutura do órgão ou do complexo orgânico que será auxiliado, pois, se assim o fosse, ter-se-ia a esdruxularia de contar com um Poder Municipal integrado por um órgão estadual nos mais de cinco mil e quinhentos Municípios brasileiros.

Mas mesmo sem esse adminículo irretrucável, uma vez que se encontra na própria Constituição que se pretende interpretar, já de há muito, alguns ilustres autores mais antigos, como PONTES DE MIRANDA e CASTRO NUNES, referidos por JARBAS MARANHÃO, se mostravam intrigados com o problema desta "posição entre os Poderes", mas concordavam ambos, depois de exporem suas respectivas razões de perplexidade, que não cabendo em nenhum deles, mas sendo responsável por fiscalizá-los, a única posição taxinômica plausível para o Tribunal de Contas seria fora de todos eles, uma vez que sua "criação posterior à teoria da separação dos poderes e fruto da prática, destoa das linhas rígidas da tripartição", concluiria ainda PONTES, com todo seu talento antecipativo. ${ }^{58}$

E assim encerra esse artigo, JARBAS MARANHÃO, tecendo suas próprias considerações: "Talvez por isso que a Constituição italiana o tenha qualificado como órgão auxiliar da república - da República, e não deste ou daquele de seus poderes; e a Constituição brasileira de 1934 o haja definido como "órgão de cooperação nas atividades governamentais".${ }^{59}$

Vê-se, pois, que o conceito de auxiliar nada tem a ver com o de subordinação e, muito menos, com o de integração (ainda porque, se fosse este o caso, restaria definir em qual dos Poderes seria absorvido, afinal, o Tribunal de Contas), bastando, para tanto, remontar ao elenco das funções constitucionais acima analisadas para se certificar que, na verdade, as cortes de contas auxiliam a todos os Poderes e a todos os órgãos constitucionalmente autônomos, estendendo seu auxílio até a outros entes da Federação (art. $31, \S 1^{\circ}$ e art. 161, parágrafo único, CF).

57 ADInMC 1.779-PE (DJU de 22.05.98); ADIn 849-MT, (RTJ 153/73); ADInMC 1.964-ES (acórdão ainda não publicado).

58 Apud JARBAS MARANHÃO. A Constituição de 1988 e o Tribunal e Contas: seus primórdios, normas e atribuições, Revista de Informaçāo Legislativa, A. 30, n. 119, jul./set. 1993, p. 267

59 Op. cit. p. 48. 
Como se deduz do exposto, o Tribunal de Contas, em cada nível federativo em que se apresente, é órgão constitucional cooperador plural e onímodo de toda a administração financeiro-orçamentária, não se subsumindo a qualquer um dos Poderes do Estado no desempenho de sua atuação juspolítica.

O mesmo ocorre, como foi atrás lembrado, com inúmeros órgãos constitucionalmente autônomos já criados como, no Brasil, as funções essenciais à justiça e, no exterior, a Corte Constitucional, na Alemanha; o Banco Federal de Reserva, nos Estados Unidos; e outras tantas outras entidades independentes que transcendem, em vários países e em diferentes Constituições, o velho esquema tripartite adotado para os complexos orgânicos de poder descritos por MONTESQUIEU.

Em sólido reforço dessa conclusão e como contribuição derradeira à questão da independência do Tribunal de Contas, transcreve-se a douta lição de RICARDO LOBO TORRES, reiterada em sua recentíssima edição do acatado Tratado de Direito Constitucional Financeiro e Tributário, do ano $2000 .^{60}$

"O Tribunal de Contas, a nosso ver, é órgão auxiliar dos Poderes Legislativo, Executivo e Judiciário, bem como da comunidade e de seus órgãos de participação política: auxilia o Legislativo no controle externo, fornecendo-lhe informações, pareceres e relatórios; auxilia a Administração e o Judiciário na autotutela da legalidade e no controle interno, orientando a sua ação e controlando os responsáveis por bens e valores públicos. Rui Barbosa já lhe indicava essas características ao defini-lo como " um mediador independente posto de permeio entre o Poder que autoriza periodicamente a despesa e o Poder que quotidianamente a executa, auxiliar de um e outro, que, comunicando com a legislatura e intervindo na administração, seja não só o vigia, como a mão forte da primeira sobre a segunda, obstando a perpetração das infrações orçamentárias por um voto oportuno" - "É imensa a doutrina, assim brasileira que estrangeira, favorável à colocação do Tribunal de Contas como órgão auxiliar dos Poderes do Estado, principalmente do Legislativo e do Executivo. Demais disso, o Tribunal de Contas auxilia a própria comunidade", uma vez que a Constituição Federal aumentou a participação do povo no controle do património público e na defesa dos direitos difusos. O Tribunal de Contas, por conseguinte, tem o seu papel dilargado na democracia social e participativa e não se deixa aprisionar no esquema da rígida separação de poderes. ${ }^{61}$ (sic)

\section{Conclusões}

Os Tribunais de Contas e os Conselhos de Contas têm natureza jurídica de

$602^{\mathrm{a}}$ edição, revista e atualizada.

61 RICARDO LOBO TORRES, Tratado de Direito Constitucional, Financeiro e Tributário, Rio de Janeiro, Ed. Renovar, 2000, Vol. V, O Orçamento na Constituiçāo, pp. 358 e 359. 
órgãos estatais de matriz constitucional, com autonomia administrativa, financeira e orçamentária, e se situam como órgãos independentes dos demais órgãos que estruturam os Poderes das entidades políticas a que pertençam, o que vem a ser uma característica constitucional que lhes é imprescindível para o exercício de suas funções de controle sobre todos e cada um deles, bem como sobre quaisquer outros entes ou órgãos, sejam públicos ou privados, que devam prestar contas de dinheiros públicos. 